\title{
Scrotal collections: pictorial essay correlating sonographic with magnetic resonance imaging findings
}

\author{
Coleções na bolsa testicular: ensaio iconográfico correlacionando achados ultrassonográficos \\ com a ressonância magnética
}

\section{Daniel de Almeida Queiroz Prata Resende ${ }^{1}$, Luís Ronan Marquez Ferreira de Souza ${ }^{2}$, Isabela de Oliveira Monteiro $^{3}$, Marcel Henrique de Souza Caldas ${ }^{4}$}

Resende DAQP, Souza LRMF, Monteiro IO, Caldas MHS. Scrotal collections: pictorial essay correlating sonographic with magnetic resonance imaging findings. Radiol Bras. 2014 Jan/Fev;47(1):43-48.

Abstract The present study is aimed at describing scrotal collections observed at ultrasonography and magnetic resonance imaging. The authors describe the main features of hydrocele, hematocele and pyocele, as well as the most common causes, clinical manifestations and associated diseases, with a brief review of the embryology and anatomy of the scrotum. Collections are frequently found in the evaluation of the scrotum, which is often performed on an emergency basis, and in most cases can be differentiated by means of imaging studies. With the consolidation of magnetic resonance imaging as the method of choice complementary with ultrasonography, the authors also describe magnetic resonance imaging findings of scrotal collections as well as the situations where such method is indicated.

Keywords: Testis; Testicular hydrocele; Hematocele; Abscess; Ultrasonography: Magnetic resonance imaging.

Resu mo O objetivo deste trabalho é descrever coleções na bolsa testicular vistas na ultrassonografia e na ressonância magnética. São descritas as principais características da hidrocele, hematocele e piocele, assim como as causas mais comuns, manifestações clínicas e doenças associadas, com uma breve revisão da embriologia e anatomia da bolsa testicular. Coleções são achados frequentes na avaliação da bolsa testicular, muitas vezes realizada em caráter de urgência, e podem ser diferenciadas por meio de exames de imagem. Com a consolidação da ressonância magnética como exame de escolha em complemento à ultrassonografia, são também descritas as características das coleções escrotais na ressonância magnética, além das indicações para a sua realização.

Unitermos: Testículo; Hidrocele testicular; Hematocele; Abscesso; Ultrassonografia; Ressonância magnética.

\section{INTRODUCTION}

Collections represent frequent findings in the assessment of the scrotum, not only in investigations performed in emergency situations, but also on an outpatient basis. Such collections are caused by different factors ranging from physiological events to varied diseases. Such situations should be differentiated and the nature of the collections should be determined when possible. Hydrocele is the most frequently found type of collection, followed by hematocele and, most rarely, pyocele ${ }^{(1)}$.

Ultrasonography (US) with a high-frequency linear transducer $^{(2)}$ is the method of choice in the assessment of

* Study developed at Department of Imaging Diagnosis, Universidade Federal do Triângulo Mineiro (UFTM), Uberaba, MG, and at Central de Diagnóstico Ribeirão Preto (Cedirp), Ribeirão Preto, SP, Brazil.

1. MD, Resident of Radiology and Imaging Diagnosis, Universidade Federal do Triângulo Mineiro (UFTM), Uberaba, MG, Brazil.

2. $\mathrm{PhD}$, Associate Professor, Unit of Radiology and Imaging Diagnosis at Universidade Federal do Triângulo Mineiro (UFTM), Uberaba, MG, Brazil.

3. MD, Trainee Radiologist (Computed Tomography and Magnetic Resonance Imaging) at Central de Diagnóstico Ribeirão Preto (Cedirp), Ribeirão Preto, SP, Brazil.

4. MD, Trainee in Radiology and Imaging Diagnosis at Central de Diagnóstico Ribeirão Preto (Cedirp), Ribeirão Preto, SP, Brazil.

Mailing Address: Dr. Daniel de Almeida Queiroz Prata Resende. Rua 12, n 399, ap. 401, Setor Oeste. Goiânia, GO, Brazil, 74140-040. E-mail: dresende72@yahoo. com.br.

Received February 28, 2013. Accepted after revision July 19, 2013. the scrotum, with excellent spatial resolution, providing almost $100 \%$ sensitivity in the detection and differentiation of intra- and extratesticular diseases. Additionally, it has the advantage of being rapidly performed (which is imprescindible in cases of testicular emergency), is a low-cost method and does not emit ionizing radiation ${ }^{(3)}$.

The technique of scrotal ultrasonography includes longitudinal and cross-sectional B-mode scans and utilization of color Doppler. The latter is essential in the differentiation between ischemia (absence of flow) and inflammation (increased flow $)^{(1)}$, situations which are frequently found in testicular emergencies. Additionally, there are resources such as trapezoidal scanning and extended field of view. Thus, the lesions can be better delimited and the symmetry of the scrotal contents can be evaluated. Such a technique is useful in the assessment of testicular diseases.

However, in some situations, the sonographic evaluation is not conclusive. Magnetic resonance imaging (MRI) has shown to be the complementary method of choice, avoiding unnecessary interventions and reducing general costs related to the testicular disease ${ }^{(4,5)}$. The basic protocol includes the acquisition of axial, sagittal and coronal, T1- and T2weighted images, and may include supplementary T1weighted, gradient-echo images which are useful in the detection of hemorrhages ${ }^{(5,6)}$. The utilization of paramagnetic 
contrast medium is reserved for situations where noncontrast images are inconclusive ${ }^{(4-6)}$. MRI allows for a good assessment of hematomas, inflammatory cysts, infarction, abscesses, and diagnosis/staging of testicular neoplasias. Also, because of its wider field of view, MRI allows for the investigation of diseases with extension beyond the scrotum, such as scrotal fistulas ${ }^{(4)}$ and cryptorchidism ${ }^{(6)}$.

\section{EMBRIOLOGY AND ANATOMY}

The scrotum originates from genital protuberances which, under the influence of testosterone, dilate and fuse to form two testicular cavities, also called scrotum. The vaginal process starts developing at about the eighth week of fetal development, corresponding to an evagination of the parietal peritoneum, which extends caudally through the abdominal wall into the testicular cavities ${ }^{(3)}$. Through the vaginal process, the testis moves down from the abdomen into the scrotum between the 7th and 9th months of the fetal life. Once the testes have descended, the vaginal process is obliterated, and its scrotal portion remains as a cavity, the tunica vaginalis. Failure of the testes to descend and patency or incomplete closure of the vaginal process may result in cryptorchidism, inguinoscrotal hernia and hydrocele ${ }^{(1)}$.

The tunica vaginalis involves the testis, with exception of its posterior aspect, and is constituted by a visceral por- tion surrounding the testis and a parietal layer in contact with the scrotal wall. The visceral layer of the tunica vaginalis is imperceptibly mixed with the tunica albuginea. Different pathological processes may affect such space, with predominance of collections ${ }^{(3)}$. The presence of a small amount of fluid $(1-2 \mathrm{ml})$ is normal ${ }^{(1)}$ and may be found at ultrasonography in more than $86 \%$ of asymptomatic men ${ }^{(3)}$.

\section{COLLECTIONS}

Hydrocele

It is an abnormal collection of serous fluid located between the visceral and parietal layers of the tunica vaginalis, but also may be adjacent to the spermatic cord. At US, the hydrocele fluid is most commonly anechoic (Figure 1), and may present subtle echoes or fibrin septa ${ }^{(2)}$ (Figure 2). In cases of chronic collections, findings of thickened walls and development of calculi may be added ${ }^{(7)}$.

At MRI, hydroceles present the typical behavior of liquids, with homogeneously low signal on $\mathrm{T} 1$-and high signal on T2-weighted sequences (Figure 3). Septations and calculi may also be identified.

In children, hydrocele is the most common cause of painless scrotal edema ${ }^{(1)}$, but it may be associated with pain or diffuse discomfort ${ }^{(7)}$. Theoretically, in neonates, all hydroceles are congenital and associated with a patent vagi-
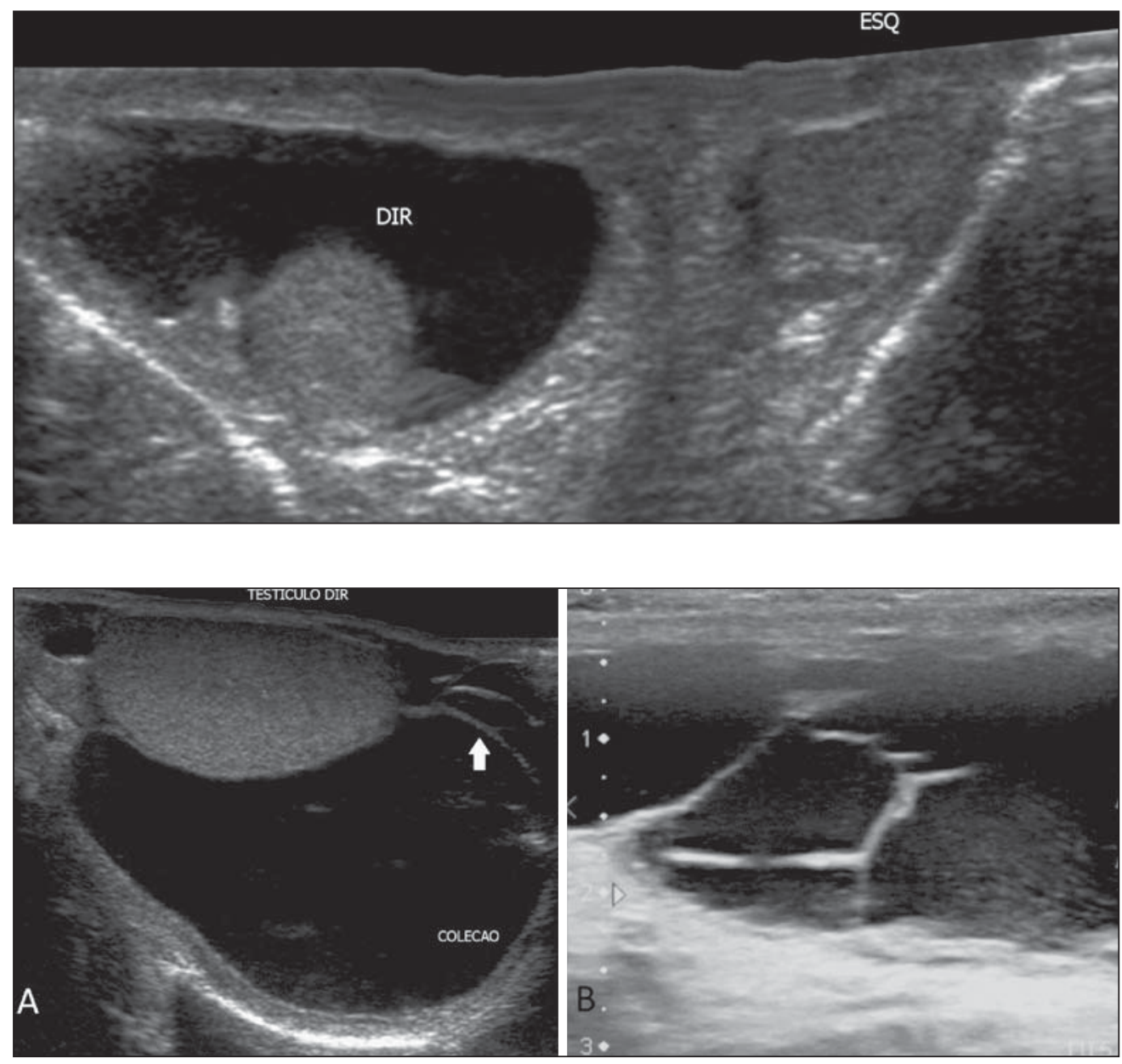

Figure 1. B-mode US image with extended field of view in a neonate: homogeneous hydrocele at right, and usual aspect of the left scrotum. Observe that the collections does not extend toward the posterior region of the testis. 

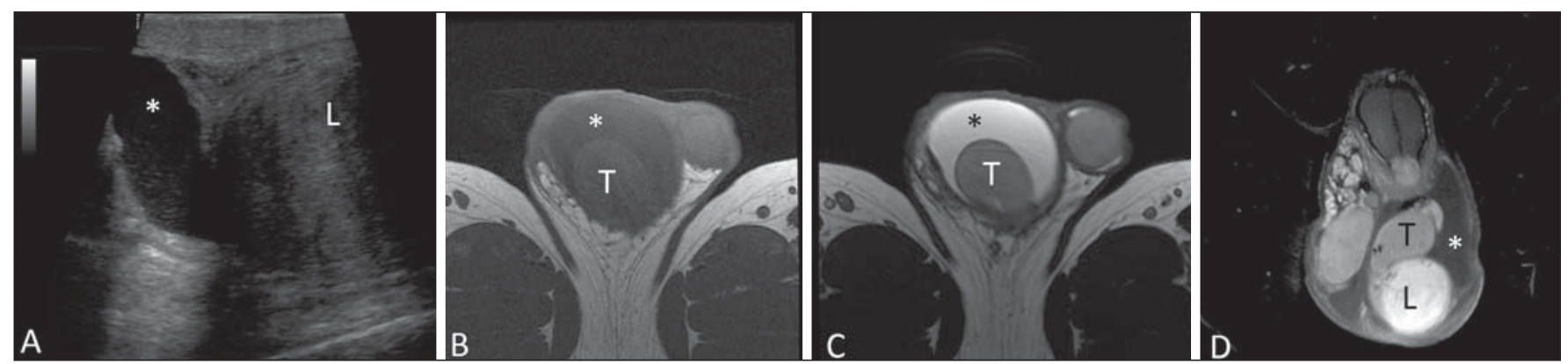

Figure 3. Hydrocele secondary to extratesticular leiomyoma. B-mode US image of right scrotum (A): hydrocele (asterisk) adjacent to the leiomyoma (L). B,C,D: Magnetic resonance imaging demonstrating the hydrocele behavior at different weightings, with low signal intensity on T1-weighted (B) as compared with high signal on T2-weighted image (C) and absence of enhancement on T1-weighted image after contrast agent injection (D). Observe the physiological amount of fluid within the left scrotum.

nal process that allows the passage of peritoneal fluid into the scrotum (Figure 4). About $80 \%$ of congenital hydroceles resolve in up to two years. The vaginal process closure above the testis and below the inner inguinal ring leads to a less common type of hydrocele, that is also known as spermatic cord cyst, which is seen as a fluid collection along the cord (Figure 5).

Abdominoscrotal hydrocele is extremely uncommon, with about 80 reported cases. It is described as a large collection protruding through the inner inguinal ring by means of an unknown mechanism and is clinically manifested as an abdominoscrotal communicating mass. Both abdominoscrotal hydroceles and spermatic cord cysts require surgical treatment.

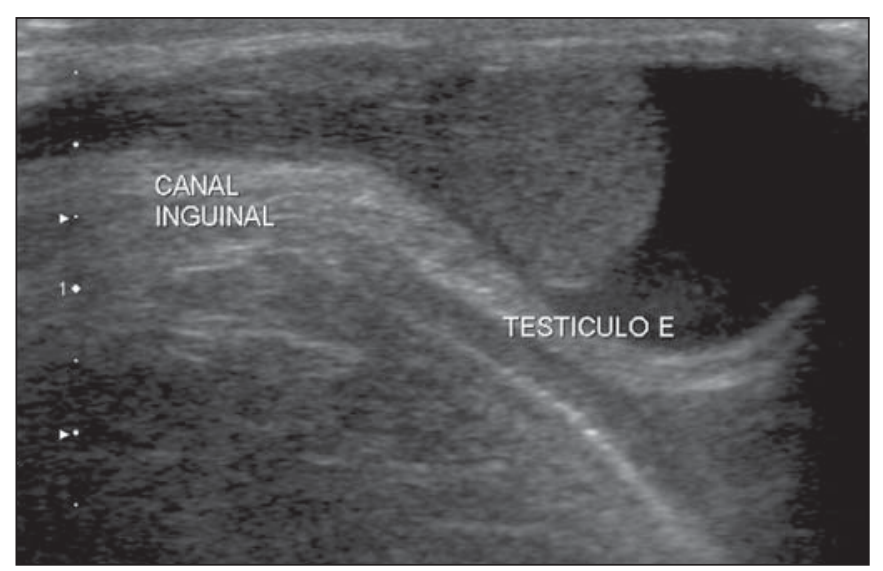

Figure 4. Congenital hydrocele. B-mode US image of an one-month-old infant: incomplete left testis descent (the testis is near the distal orifice of the inguinal canal) in association with hydrocele.
In older children, adolescents and adults, hydrocele is usually acquired and related to inflammatory processes, testicular torsion, trauma, tumor ${ }^{(1)}$, or may be idiopathic. The idiopathic hydrocele mechanism is still unknown, but it is believed that it results either from an imbalance between the fluid production and reabsorption, or from the absence of efferent lymphatics ${ }^{(7)}$.

In cases of testicular torsion, the presence of hydrocele may demonstrate a failure in the fixation of the testis to the scrotal wall - bell-clapper deformity (Figure 6) -, which allows free movement of the testis within the scrotum, thus increasing the chance of torsion. Such a condition is rather associated with testicular torsion in the peripuberal period (the other peak of testicular torsion incidence occurs in the perinatal period $)^{(2)}$.

Some differential diagnoses must be taken into consideration, namely, indirect inguinal hernia, where the presence of fluid and gas involved by the bowel loop wall is observed

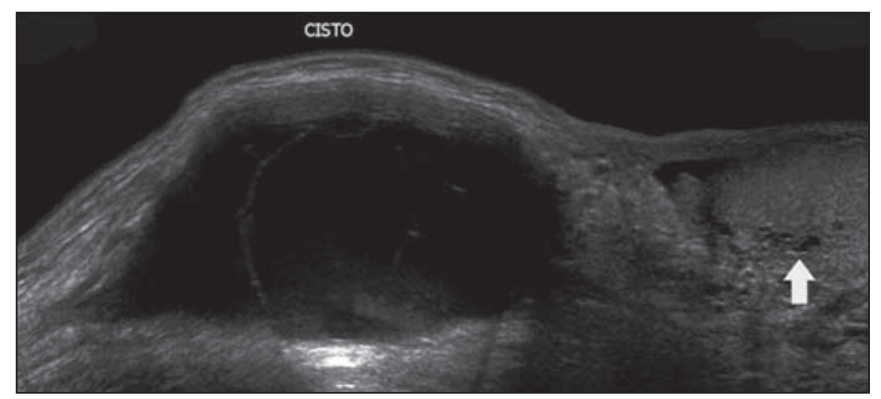

Figure 5. B-mode US with extended Field of view: spermatic cord cyst in association with rete testis ectasia (arrow) and adjacent physiological amount of fluid.
Figure 6. B-mode US image of a two-month-old infant. Bilateral hydrocele and bell clapper deformity: the right testis is completely surrounded by fluid, with failure in the fixation of the testis to the scrotal wall $(\mathbf{A})$, as compared with the left testis with normal fixation (B).
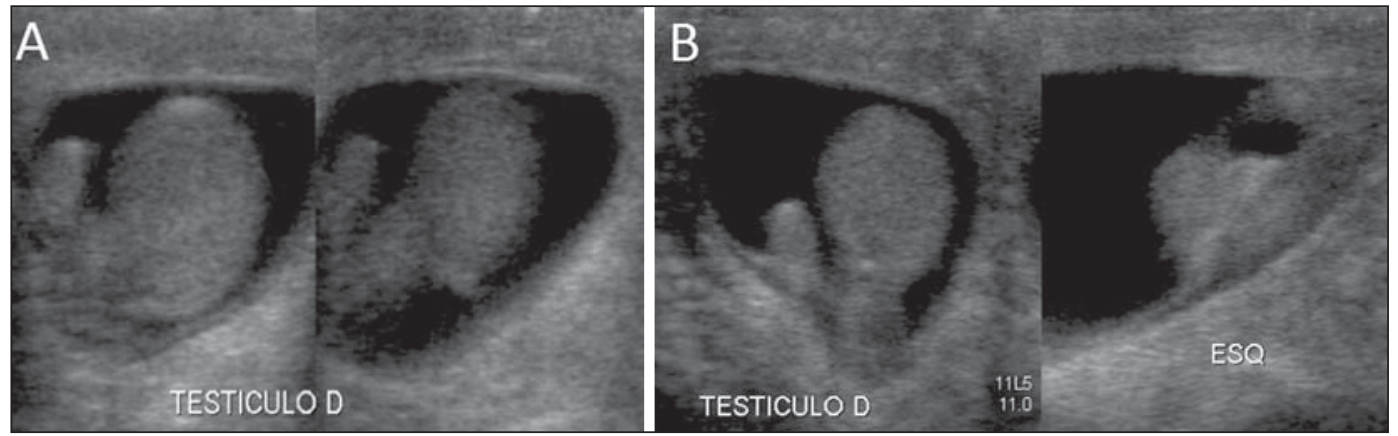
(Figure 7); spermatocele, located in the epidydimal head and containing small, fluctuating echoes corresponding to spermatozoids (Figure 8); and acute hematoceles and pyoceles.

\section{Hematocele}

It is defined as accumulation of blood within the tunica vaginalis. Clinically, it presents as a hardened mass or a little

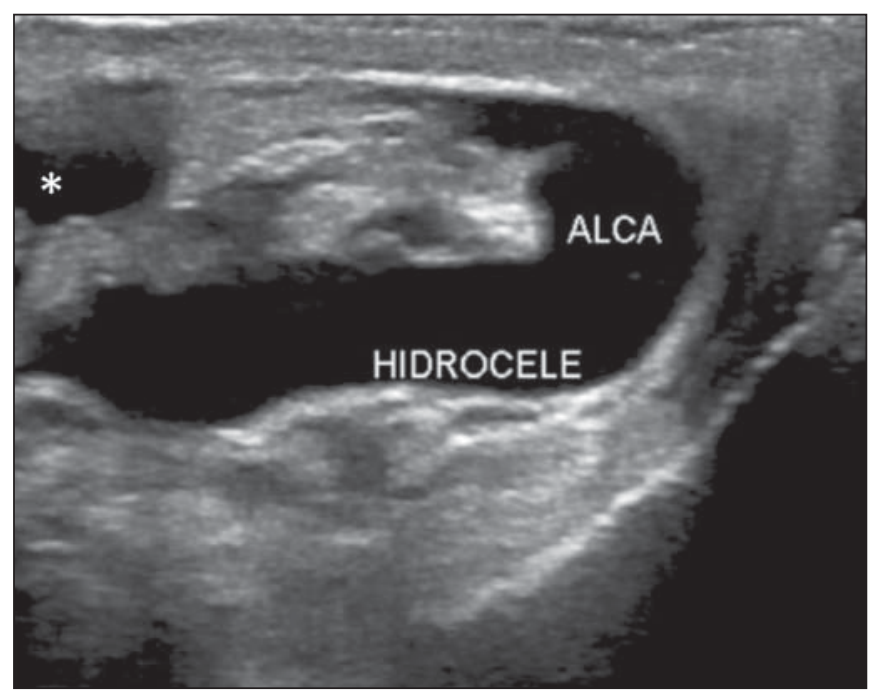

Figure 7. Inguinal hernia associated with hydrocele. B-mode US showing an irregular mass with thickened walls, containing a small amount of fluid, and surrounded by free fluid with anechoic appearance.

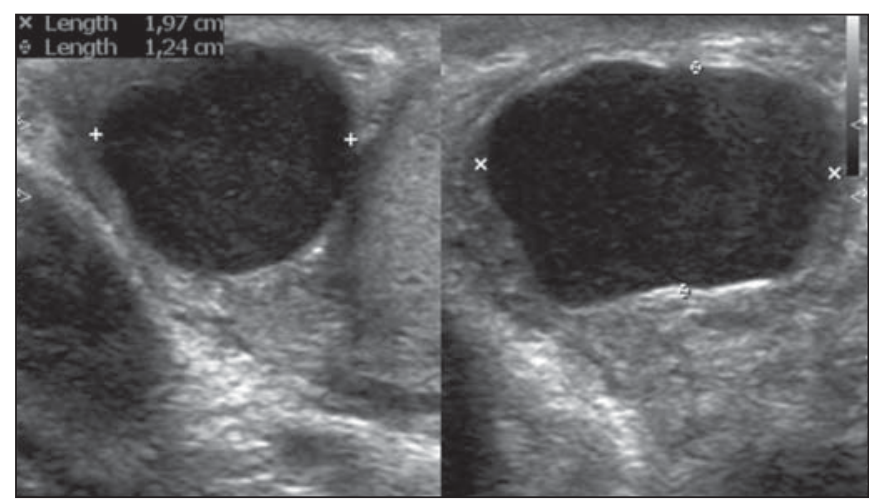

Figure 8. Spermatocele. B-mode US image: cyst with slightly lobulated margins, anechoic contents, with small fluctuating echoes (spermatozoids), located in the epidydimis. Observe the location and delimitation of the lesion. scrotal discomfort. In most cases, the condition presents spontaneous regression with conservative treatment ${ }^{(3)}$, but at a long term, conservatively approached and non-diagnosed voluminous hematoceles and testicular hematomas may result in infection, pain or atrophy ${ }^{(8)}$.

At US, hematocele has variable presentations, depending on the time following the trauma ${ }^{(9)}$. Acute hematocele has a fluid-like and hyperechoic appearance (Figure 9) and, after two weeks, it liquifies and may take a cystic appearance $^{(5)}$ with complex septations ${ }^{(7)}$, fluid-fluid level and subtle echoes $^{(8)}$ (Figure 10). US had $87 \%$ specificity and $89 \%$ sensitivity in the diagnosis of hematocele as compared with intraoperative findings ${ }^{(2)}$.

MRI findings follow the pattern of methemoglobin degradation in other tissues (Table 1). The T2-weighted images may have a variable appearance, and chronic hematomas may present with a hyposignal halo secondary to hemosiderin deposition $^{(5)}$ (Figure 11). Magnetic resonance imaging is also important in the detection of tunica albuginea rupture, which indicates surgical intervention in cases of testicular trauma $^{(4)}$.

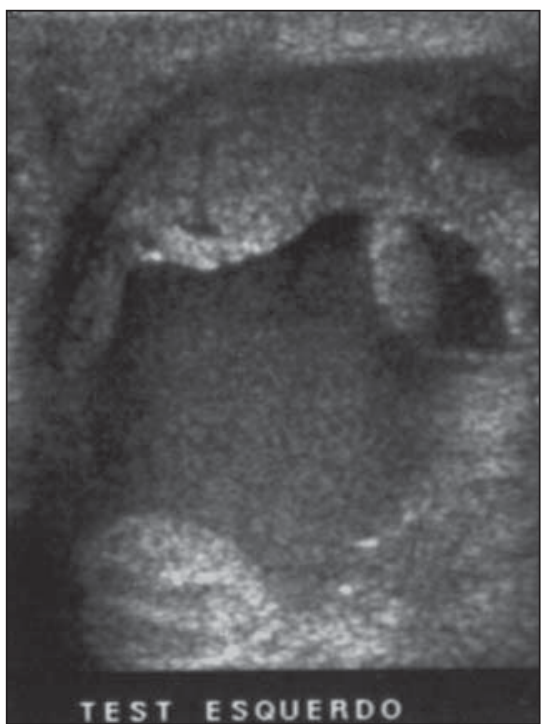

Figure 9. B-mode US image. Acute hematocele secondary to trauma, with an echogenic fluid collection within the left scrotum.
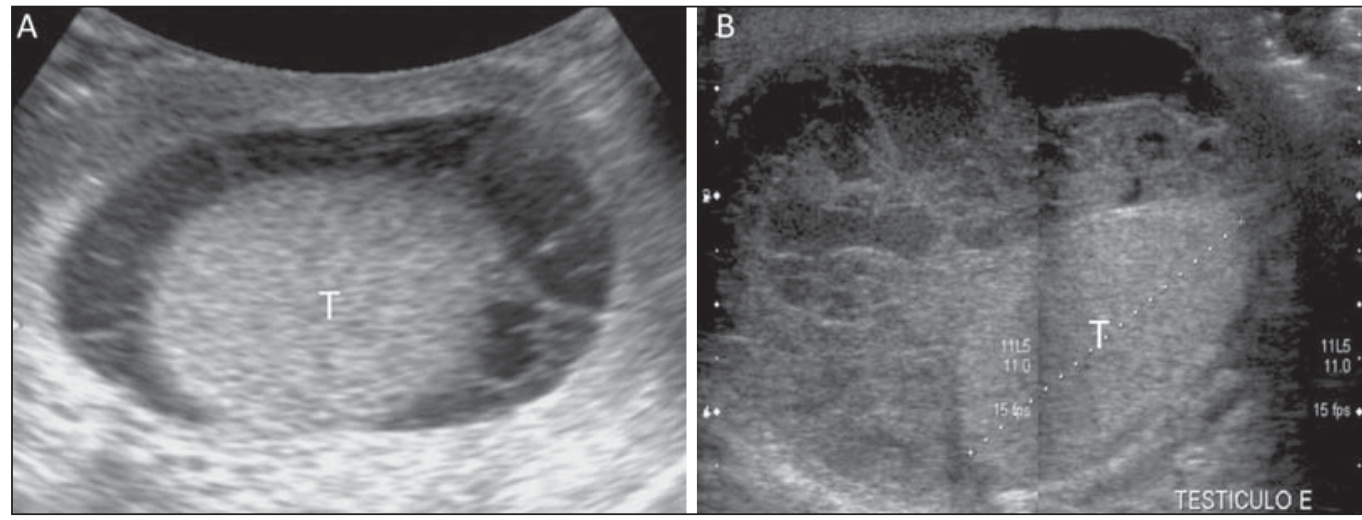

Figure 10. Organizing hematocele following trauma (A) and vasectomy (B) at B-mode US. Collections surrounding the testes $(\mathrm{T})$, with hyperand hypoechoic areas with thickened septa, fluid-fluid level and subtle echoes in suspension. 

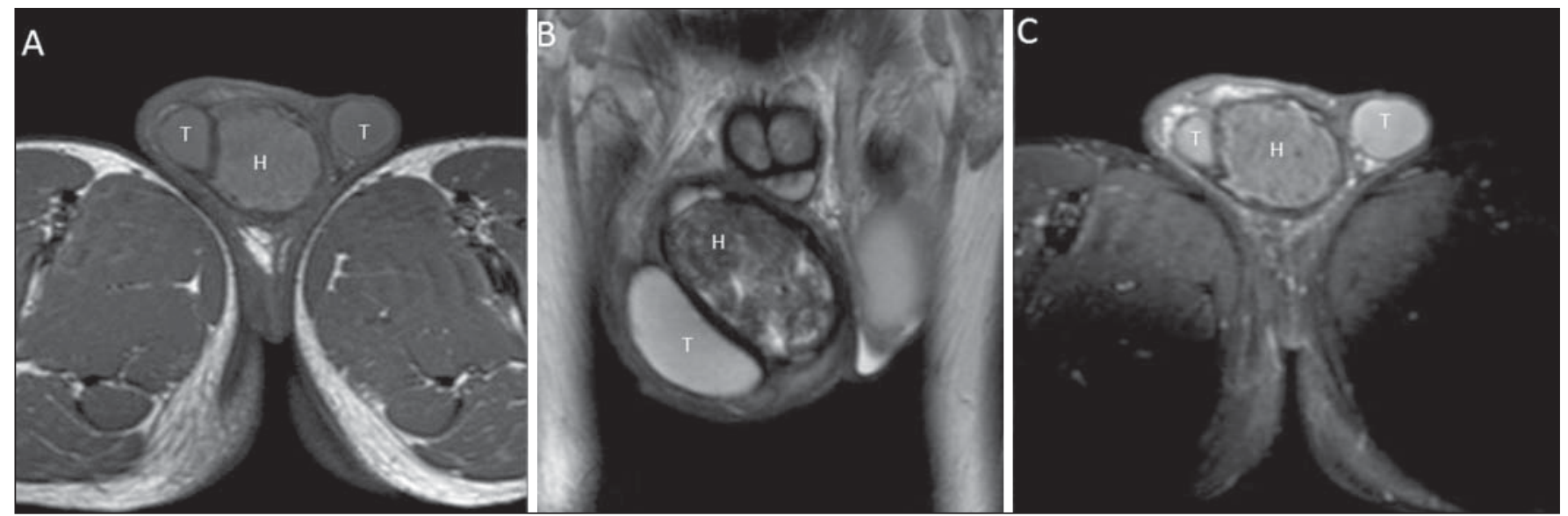

Figure 11. Scrotal MRI demonstrating hematocele $(\mathrm{H})$, axial, T1-weighted images before $(\mathbf{A})$ and after contrast injection $(\mathbf{C})$ and coronal T2-weighted image (B). Heterogeneous collection with iso/hyposignal on T1- and hyposignal on T2-weighted image in relation to the testes (T). T2-weighted image demonstrates areas of hypersignal and marked hyposignal compatible with hemoglobin at different phases of degradation. There is no contrast-enhancement of the collection.

Table 1—Phases of hemoglobin degradation and corresponding signal at MRI.

\begin{tabular}{lcc}
\hline Phase & $\begin{array}{c}\text { T1-weighted } \\
\text { signal }\end{array}$ & $\begin{array}{c}\text { T2-weighted } \\
\text { signal }\end{array}$ \\
\hline Oxyhemoglobin & Low & High \\
Deoxyhemoglobin & Low & Very low \\
Intracellular methemoglobin & High & LOw \\
Extracellular methemoglobin & High & High \\
\hline
\end{tabular}

The main causes of hematocele include trauma, tumor, torsion and surgery ${ }^{(3)}$. In neonates, such condition may be secondary to intra- and extraperitoneal abdominal bleedings. In such age range, the finding of non-traumatic hematocele should lead to the investigation of abdominal foci, since there are reports in the literature about hematocele secondary to adrenal hemorrhage $\mathrm{e}^{(10,11)}$

Testicular trauma is the most common cause of hematocele and the third most common cause of acute scrotal pain. The right testis is most frequently affected, probably because of its location slightly above the left testis in most men, which facilitates its compression against the pelvis ${ }^{(8)}$. It may be caused by intra- or extratesticular bleeding and not rarely hematocele and intratesticular hematoma are found on a single study; and for this reason it is nonspecific for testicular rupture ${ }^{(9)}$.

In the pediatric age range, hematocele may also be secondary to abdominal traumas ${ }^{(8)}$. A subtle trauma may go unnoticed and, in such cases, the bleeding is frequently associated with varicoceles, with rupture of a dilated vessel ${ }^{(3)}$.

The acute onset of a voluminous hematocele may reduce the testicular blood flow due extrinsic vessels compression, mimicking a partial or even complete torsion, requiring drainage of the collection ${ }^{(8)}$. Additionally, large collections make the tunica albuginea identification more difficult at US and may lead to false-negative diagnoses of intratesticular hematoma where, in fact, hematocele is present ${ }^{(2)}$. The identification of an intact tunica albuginea allows for ruling out the presence of testicular rupture ${ }^{(8)}$.

\section{Pyocele}

Most frequently, pyocele occurs as a complication of orchiepidydimitis, particularly in cases where the latter crosses the mesothelial layer of the tunica vaginalis ${ }^{(3)}$, or secondarily to a reactive infected hydrocele ${ }^{(6)}$. The patients present with acutely swollen and painful scrotum, frequently in association with fever and leukocytosis.

At US, orchitis leads to a diffuse increase in volume with decreased testicular echogenicity. The presence of focal areas of marked decrease in echogenicity indicates the development of abscess ${ }^{(3)}$, in association with increased peripheral flow at color Doppler ${ }^{(6)}$. Pyocele is seen as a complex, heterogeneous fluid collection (Figure 12). Gas may be present, causing echogenic, specular reflections and shadowing $^{(3)}$. The utilization of color Doppler may be useful in some cases, particularly where testicular collections cannot be distinguished from tumor-like masses. Like in the investigation of spermatoceles and ovarian teratomas, Doppler US demonstrates internal echoes moving in the contrary direc-

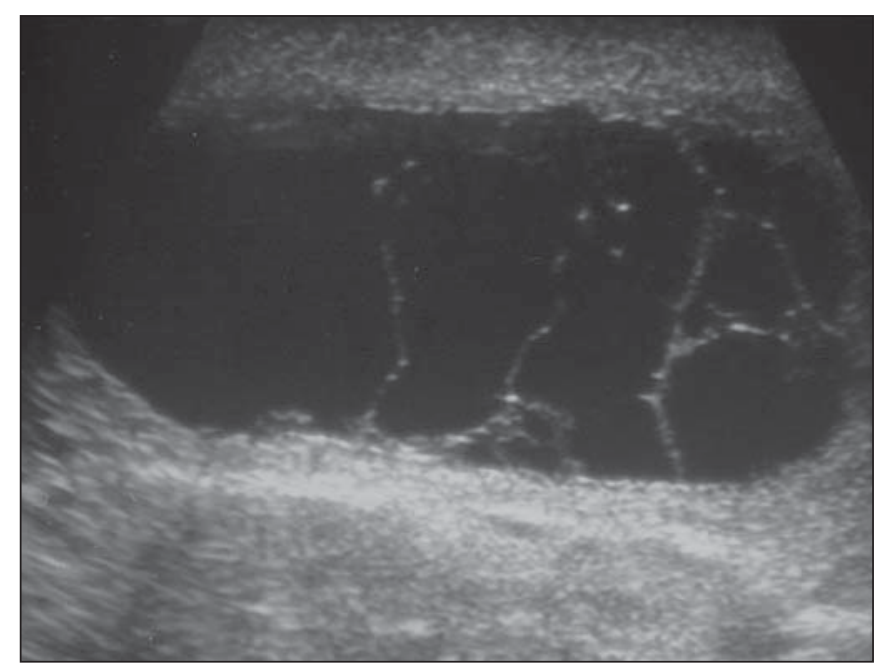

Figure 12. B-mode US image. Collection with multiple, incomplete septa inside, in a patient with hyperemia and pain in the scrotum. 

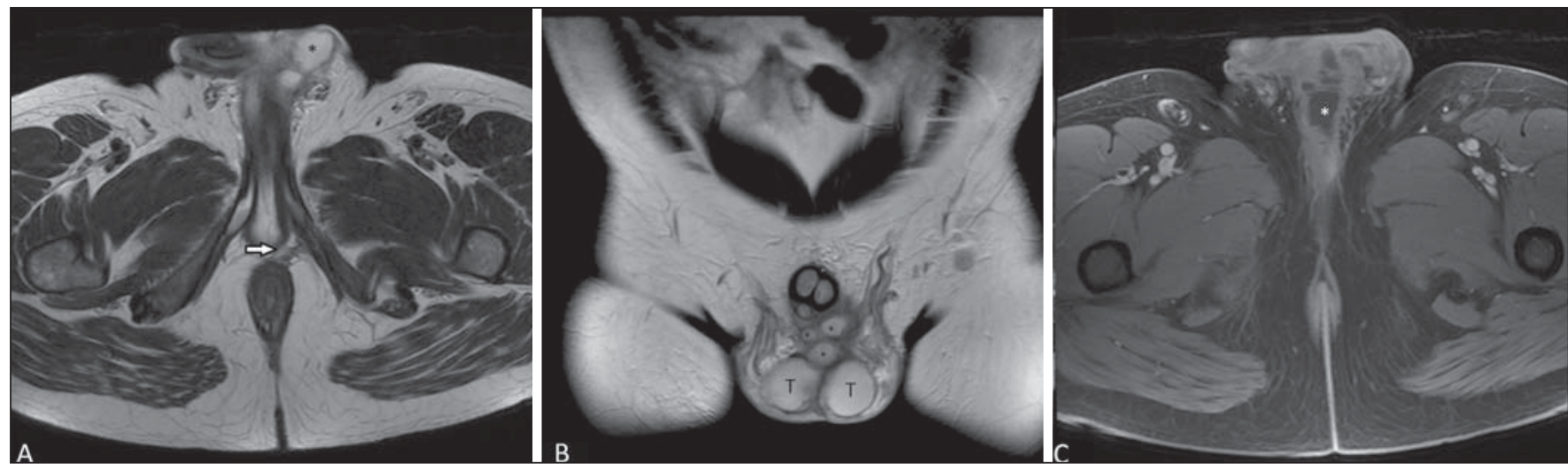

Figure 13. MRI. Presence of an abscess in the left scrotum with rectal fistula. A,B: Axial (A) and coronal (B) sections of T2-weighted sequence where a multiloculated collection is observed with hypersignal in the left scrotum (asterisk) without extension to the testes (T), and fistulous tract (arrow) which crosses the anal sphincter muscle towards the anterior rectal wall. Axial T1-weighted image after contrast agent injection (C) demonstrating hyposignal from the collection (asterisk) and the enhancement of its walls. The large field of view provided by MRI facilitates the assessment of the lesion extent.

tion of the transducer - a finding that is described as "falling snow" sign ${ }^{(12)}$.

Considering that in most cases pyocele is secondary to testicular inflammatory processes, the diagnosis depends on the recognition of such processes. Typically, at MRI, abscesses present hyposignal on $\mathrm{T} 1$ - and hypersignal on T2-weighted sequences, which is characteristic of fluid contents, with a halo of hypersignal on T2-weighted sequences. On contrastenhanced images, only the perilesional parenchyma presents with intense enhancement (Figure 13).

Possible complications include: Fournier's gangrene, necrotizing and potentially fatal perineal infection. Frequently, patients with scrotal abscess have a history of diabetes, HIV infections or other immunosuppressive conditions. Anaerobic and gas-producing bacteria, including those of the Clostridium genus are the main etiological agents of such a condition ${ }^{(3)}$.

\section{CONCLUSION}

US is the first method of choice in the assessment of the scrotum, frequently demonstrating collections. The present essay was aimed at demonstrating imaging findings which allows for the differentiation of hydrocele, hematocele and pyocele, besides describing common causes and clinical characteristics which may be associated with such findings. It is important to highlight that, in some situations, sonographic findings alone do not allow the distinction of the material contained in the collection, so the clinical history and physical examination of the patient play a relevant role in the final diagnosis. History and time span from the trauma, previous surgeries and comorbidities must not be neglected. As the wide utilization of US is added to the high incidence of scrotal collections, it is important to be familiar with the characteristics of each collection.
With the MRI consolidation as a method to solve doubts in the diagnosis of testicular diseases, it is important that radiologists are aware of the signal characteristics which allow the differentiation of each disease.

\section{REFERENCES}

1. Aso C, Enríquez G, Fité M, et al. Gray-scale and color Doppler sonography of scrotal disorders in children: an update. Radiographics. 2005;25:1197-214.

2. Guichard G, El Ammari J, Del Coro C, et al. Accuracy of ultrasonography in diagnosis of testicular rupture after blunt scrotal trauma. Urology. 2008;71:52-6.

3. Woodward PJ, Schwab CM, Sesterhenn IA. From the archives of the AFIP: Extratesticular scrotal masses: radiologic-pathologic correlation. Radiographics. 2003;23:215-40.

4. Parenti GC, Feletti F, Brandini F, et al. Imaging of the scrotum: role of MRI. Radiol Med. 2009;1 14:414-24.

5. Kim W, Rosen MA, Langer JE, et al. US MR imaging correlation in pathologic conditions of the scrotum. Radiographics. 2007;27:123953.

6. Cassidy FH, Ishioka KM, McMahon CJ, et al. MR imaging of scrotal tumors and pseudotumors. Radiographics. 2010;30:665-83.

7. Schul MW, Keating MA. The acute pediatric scrotum. J Emerg Med. 1993;11:565-77.

8. Bhatt S, Dogra VS. Role of US in testicular and scrotal trauma. Radiographics. 2008;28:1617-29

9. Vital RJ, Mattos LA, Souza LRMF, et al. Aspectos ultra-sonográficos das alterações não-neoplásicas do testículo. Radiol Bras. 2007;40: $61-7$

10. Gonçalves R, Abuabara A, Abuabara RF, et al. Scrotal hematoma as a sign of adrenal hemorrhage in newborns. Sao Paulo Med J. 2011 ; 129:113-5.

11. Ibáñez Godoy I, Mora Navarro D, Delgado Rioja MA, et al. Hematoma escrotal unilateral. An Pediatr (Barc). 2004;60:477-8.

12. Mahmood NS, Suresh HB. Role of Doppler sonography in uncovering the testis within a pyocele: the "falling snow" sign. J Ultrasound Med. 2009;28:557. 